American J. of Engineering and Applied Sciences 3 (4): 723-727, 2010

ISSN 1941-7020

(C) 2010 Science Publications

\title{
Ceppo Morelli Block-Falls Probability Study to Support the Decision of Excavating a by-Pass Tunnel
}

\author{
${ }^{1}$ S. Longo and ${ }^{2} \mathrm{P}$. Oreste \\ ${ }^{1}$ Geotechnical Center of Institute Superior Technical, \\ Technical University of Lisbon, Portugal \\ ${ }^{2}$ Politecnico di Torino, Italy
}

\begin{abstract}
Problem statement: In this article, some important aspects linked to the new Ceppo Morelli (Piemonte, Italy) future by-pass tunnel construction were considered. Approach: The article concerned a mountainous region which in the past was affected by slope landslides and block falls that reached a downhill roadway and two nearby villages. Results: Using risk analysis approach the probability of block-falls down the mountain slopes was accomplished, with estimation of their trajectories. Conclusion: Obtained results proved the need to open the new tunnel because the present roadway is not considered risk free.
\end{abstract}

Key word: Block falls, risk analysis, rock block trajectories, probabilistic analysis

\section{INTRODUCTION}

Ceppo Morelli is located at the bottom of the southern slope of the Monte Rosa Montain, in Anzasca Valley (north of Italy) (Fig. 1). Only one national road, the N549 road, connects Ceppo Morelli to the other cities. Prequartera and Campioli, two small villages near Ceppo Morelli and the section of national road between them are continuously affected by rock-falls from the Monte Rosa slope. The quoted area is also affected by the risk of being struck by a large landslide (Scavia, 2004). This last hypothesis turned more realistic when a large ancient landslide located in the Monte Rosa middle-low southern slope (within the altitudes 1850 and 1200 mosl) (Piteau and Clayton, 1977) was reactivated by intense rainfall in October 2000 (Biancotti and Bovo, 1998). The total surface of the hypothetical rockslide is $160.000 \mathrm{~m}^{2}$ and the estimated total volume is between 4 and $6 \times 10^{6} \mathrm{~m}^{3}$ (Piteau and Clayton, 1977).

Several boulders reached the bottom of the valley and the national road N549; some of them stopped nearby some buildings of the villages Prequartera and Campioli. After the rock fall originated by the October 2000 rainfall a diversion road was built on the opposite side of the valley to reactivate the transit and to avoid the risk for vehicles to be affected (Fig. 1).

This study shows that the road diversion constructed is not completely risk free. The probability of the diversion being hit or overtaken by large blocks was calculated by a risk analysis approach.
A definitive solution to the problem of rock-falls reaching the N549 is connecting the quoted villages by a "by-pass" tunnel in order to transfer underground the transport circulation. The tunnel geometry has to consider the proximity of the existing landslide surface and the opening method must take into account the existing possibility of the instability reactivation. Figure 2 a shows the section of the tunnel in a plan view: its curve is especially designed to increase his distance from the instable surfaces; the opening method provide for a pilot tunnel opened first, with an open TBM machine in order to optimize and reduce the use of explosive in the following enlargement phase to the final section. An important role of the pilot tunnel is also to provide detailed information about the rock volumes excavated to drastically reduce the knowledge uncertainty due to the lack of investigations (the zone is now not permitted to any person).

Interesting analysis on the landslide reactivation mechanism have been done recently by Scavia (2004), here partially and synthetically resumed. The landslide upper part, delimited by a tension crack, moved due to the October 2000 rainfall; displacements of about 4-5 m were reached and caused a reaction of the middle-lower part of the slope with rock blocks separation and large rock-falls (especially at the mean altitude of 1200 mosl). Some blocks reached a volume of $300 \mathrm{~m}^{3}$. The most catastrophic hypothesis considers that the ancient landslide reactivation can lead to huge rock avalanche involving a volume of about $5 \times 10^{6} \mathrm{~m}^{3}$ of rock. This hypothesis is however extremely unlikely. 


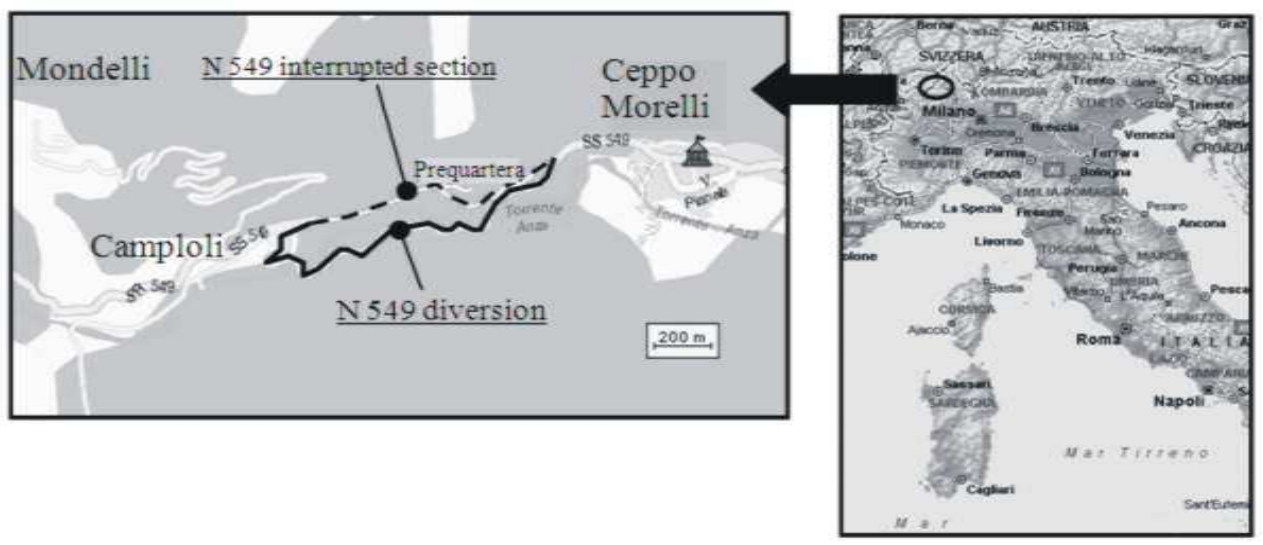

Fig. 1: Location of the study area. Key: Dashed line: Ancient section of the road affected by rock falls; Continuous line: Temporary road on the other side of the valley, recently constructed

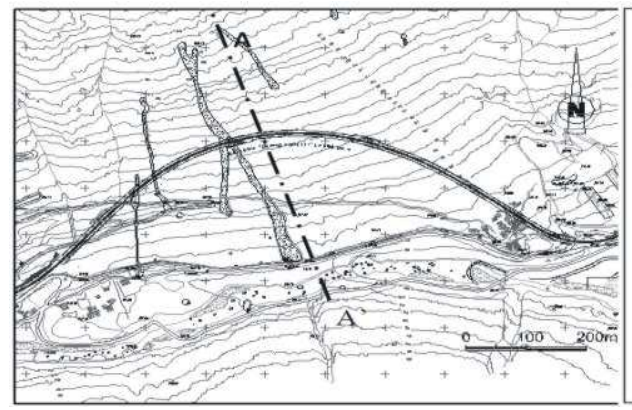

(a)

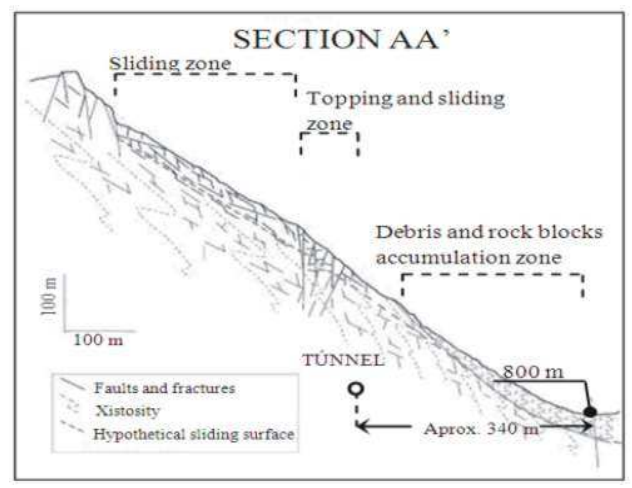

(b)

Fig. 2: (a): Tunnel course on a plan view; (b): Vertical Section A (adapted from Scavia (2004)).

\section{MATERIALS AND METHODS}

Landslide classification: To classify the Ceppo Morelli Landslide we used the Cruden and Varnes (1996) landslide classification method based on the Varnes (1984) method developed in 1984. The method defines an essential terminology to classify all the types of landslides.

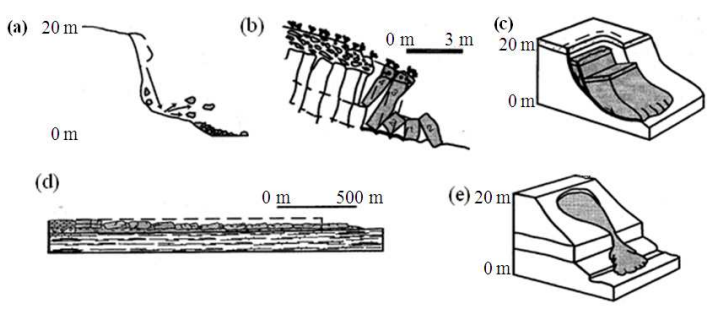

Fig. 3: Types of elementary sliding (Cruden and Varnes, 1996); (a): Fall; (b): Topple; (c): Slide; (d): Spread; (e): Flow

Table 1: Definition of natural materials (Australian Geomechanics Society, 2000)

\begin{tabular}{ll}
\hline Material types & Description \\
\hline Rock & $\begin{array}{l}\text { A hard or firm mass that was intact and in its natural } \\
\text { place before the initiation of movement } \\
\text { An aggregate of solid particles, generally of minerals } \\
\text { and rocks, that either was transported or was formed } \\
\text { by the weathering of rock in place. Gases or liquids } \\
\text { filling the pores of the soil form part of the soil } \\
\text { Describes material in which } 80 \% \text { or more of the } \\
\text { particles are smaller than } 2 \mathrm{~mm} \text {, the upper limit of } \\
\text { sand sized particles } \\
\text { Contains a significant proportion of coarse material; } \\
\text { 20- } 80 \% \text { of the particles are larger than } 2 \mathrm{~mm}, \text { the } \\
\text { remainder are less than } 2 \mathrm{~mm}\end{array}$ \\
&
\end{tabular}

For elementary types of movements are necessary only two terms: The first referring to the type of material (Table 1) and the second describing the cinematic of the instable masses (Fig. 3). To classify more complex landslides is possible to combine two or more types of elementary movements.

The name of a landslide can become more elaborate if it's necessary to describe it in a more detailed way. To complete the identification of the movement, descriptors are added in front of the twoterm classification using a preferred sequence of terms. 
Am. J. Engg. \& Applied Sci., 3 (4): 723-727, 2010

Table 2: Glossary for forming names of landslides (Cruden and Varnes, 1996)

\begin{tabular}{|c|c|c|c|}
\hline \multicolumn{4}{|l|}{ Activity } \\
\hline State & \multicolumn{2}{|c|}{ Distribution } & Style \\
\hline Active & \multicolumn{2}{|c|}{ Advancing } & Complex \\
\hline Reactivated & \multicolumn{2}{|c|}{ Retrogressive Composite } & \\
\hline Suspended & \multicolumn{2}{|c|}{ Widening } & Multiple \\
\hline Inactive & \multicolumn{2}{|c|}{ Enlarging Successive } & \\
\hline Dormant & \multicolumn{2}{|l|}{ Confined } & Single \\
\hline Abandoned & \multicolumn{2}{|c|}{ Diminishing } & \\
\hline Stabilized & \multirow{2}{*}{\multicolumn{2}{|c|}{ Moving }} & \\
\hline \multirow{2}{*}{\multicolumn{4}{|c|}{$\begin{array}{l}\text { Relict } \\
\text { Description of first movement }\end{array}$}} \\
\hline & & & \\
\hline Rate & Water content & Material & Type \\
\hline Extremely rapid & Dry & Rock & Fall \\
\hline Very rapid & Moist & Earth & Topple \\
\hline Rapid & Wet & Debris & Slide \\
\hline Moderate & Very wet & & Spread \\
\hline Slow & & & Flow \\
\hline Very slow & & & \\
\hline Extremely slow & & & \\
\hline
\end{tabular}

Mentioning the Australian Society of Geomechanics Sub-Committee on Landslide Risk Management (ASG SCLRM) the sequence suggested by Cruden and Varnes (1996), "provides a progressive narrowing of the focus of the descriptors, first by time and then by spatial location, beginning with a view of the whole landslide, continuing with parts of the movement and finally defining the materials involved. The recommended sequence, as shown in Table 2, shows activity (including state, distribution and style) followed by descriptions of all movements (including rate, water content, material and type)".

Using this classification method the Ceppo Morelli landslide is classified as.

Reactivated, confined, complex, very slow, very wet, earth and debris, flow-extremely rapid, rock and fall.

\section{RESULTS AND DISCUSSION}

Rock-fall probabilistic analysis: In this study only the rock-fall aspect of the instability is presented (Budetta and Santo, 1994). A simulation calculating the trajectories and the distances of the falling blocks on the slope and the valley was carried out using the probabilistic computer code ROTOMAP (Geo and Soft International, 2009).

The calculation of the probability that blocks intercept the N549 has been done following the steps shown in Fig. 4 (Hoek, 1987; Pasquero, 1987).

Step 1: Generate a 3D Model of the analyzed slope to be used as ROTOMAP input.
Table 3: Geomechanic parameters used for ROTOMAP input model

\begin{tabular}{llll}
\hline Type of material & $\mathrm{r}_{\mathrm{n}}$ & $\mathrm{r}_{\mathrm{t}}$ & $\mathrm{c}_{\mathrm{rs}}$ \\
\hline Talus cover with vegetation & $0.32^{*}$ & $0.80^{*}$ & 0.65
\end{tabular}

$\begin{array}{llll}\text { Detrital material mixed } & 0.45-0.65 * * & 0.5-0.86 * * & 0.65\end{array}$

with large rock boulders

$\begin{array}{llll}\text { Asphalt roadway } & 0.40 * & 0.90 * & 0.45\end{array}$

$\begin{array}{llll}\text { Riverbed (remolded } & 0.10^{* * *} & 0.27 * * * & 0.65\end{array}$

pyroclastic from the terraces)

*: Hoek (1987), Department of Transportation USA; **: Piteau and Clayton (1987); Piteau and Clayton (1977) ***: Budetta and Santo (1994)

\begin{tabular}{|c|c|c|c|}
\hline $\begin{array}{l}\text { STEP 1 } \\
\text { Generate a 3D Model of } \\
\text { the slope analysed to be } \\
\text { used as ROTOMAP input }\end{array}$ & $\longrightarrow$ & $\begin{array}{c}\text { STEP 2 } \\
\text { Model calibration using } \\
\text { back-analysis and real } \\
\text { blockfalls data }\end{array}$ & $\rightarrow \quad \begin{array}{c}\text { PTEP 3 } \\
\text { Probabilistic analysis of } \\
\text { the blocks trajectories } \\
\text { and kinetic energy }\end{array}$ \\
\hline
\end{tabular}

Fig. 4: Calculation steps to determine the probability of interception of the N549 temporary diversion by blocks

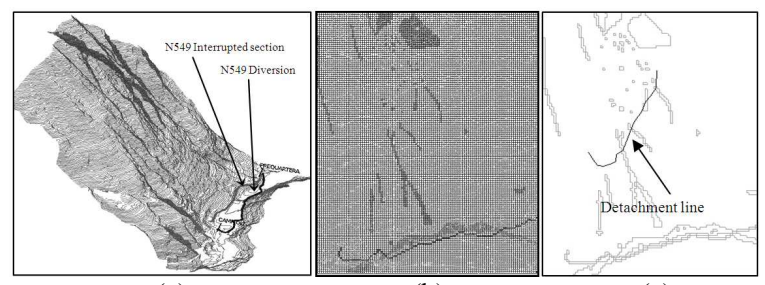

(a)

(b)

(c)

Fig. 5: Input data for ROTOMAP simulation

To obtain a ROTOMAP 3D model were introduced the following information:

- The slope topography in digital format (Fig. 5a)

- The geomechanic parameters $r_{n}, r_{t}$ (coefficients of restitution of normal and tangential energy) and $\mathrm{c}_{\mathrm{rs}}$ (friction coefficient) of the rolling-sliding boulders (Fig. 5b). The used values, reported in Table 3, were chosen on the basis of the literature and by means of corrections and adjustments carried out during the model calibration

- The "detaching line" (Fig. 5c) that is the line delimiting the lower part of the blocks detachment area. It's also necessary to introduce the intervals of initial velocity (to simulate blocks detaching anywhere in the detaching area and not only in the detaching line) and of initial angular deviation.

Step 2: Model calibration using back analysis and real block-falls data.

The data of 35 blocks of great dimensions, situated in different positions (in the hillside of PrequarteraCampioli, next to the river, in the Campioli village and in the opposing hillside) had been introduced. Surveys and photos of the area facilitated this task. 


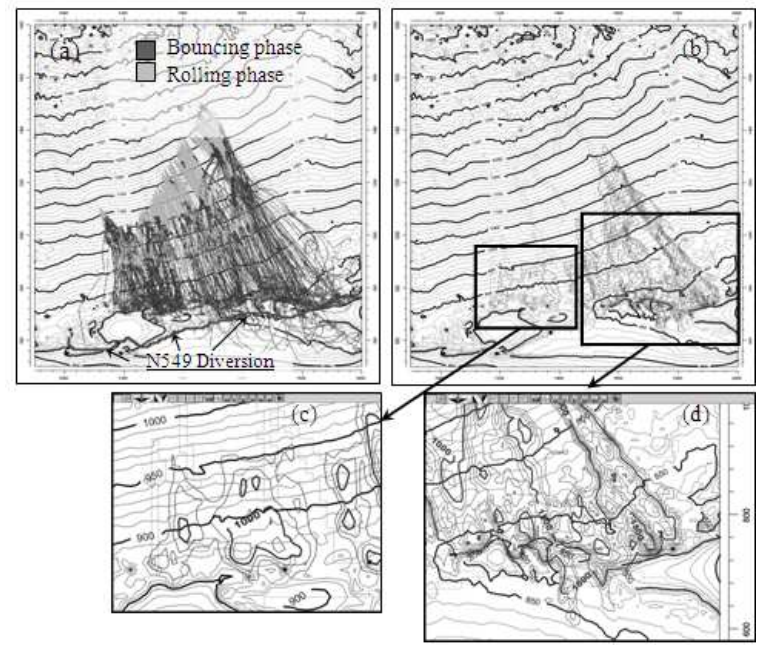

Fig. 6: ROTOMAP results. Key: (a): Blocks trajectories; (b) Kinetic energy distribution on the slope $\left(\mathrm{J} \mathrm{kg}^{-1}\right)$; (c: and $\left.\mathrm{d}\right)$ : are enlarged figures of the most meaningful areas in $b$

Step 3: Probabilistic analysis of the blocks trajectories and kinetic energy. After several reiterations of the trajectories calculation, the most representative simulation was reached. In Fig. 6a the trajectories of the blocks during the fall are presented (simulation with 640 blockfalls). About 77 trajectories on a total of 640 intercept the temporary diversion of N549 realized on the opposite side of the valley, almost all in bouncing phase and not in rolling. In Fig. 6b-d are reported the values of kinetic energy of the blocks (in $\mathrm{J} \mathrm{kg}^{-1}$ ) during their fall.

Using an historical approach combined with the results obtained with the software simulations expressed before, it is possible to estimate the frequency of blocks that reach the temporary diversion road. Considering the only block-falls happened by the year 2000, we obtained:

$\mathrm{F}_{\mathrm{qb}}=1.23$

where, $F_{q b}$ is the frequency of rock-falls per year happened in the study area.

The choice of considering the only events happened by the year 2000 is due to the fact that from that date the monitoring system of the landslide was implemented and the information about block-falls are more detailed.

Other different values of frequency can be calculated using different time intervals. It's also useful to note that the information about rock-falls that happened two hundred years ago is considered to be not so complete and detailed. Having more data about rockfalls happened in the study area is possible to improve the estimation of the frequency.

Combining $\mathrm{F}_{\mathrm{qb}}$ with the results obtained using the ROTOMAP code it was obtained:

$$
F_{b e}=1.23 \cdot \frac{77}{640}=0.147
$$

where, $F_{b e}$ is the frequency of blocks that reach the temporary diversion road; it means that one block every near 6 years and nine months can reach the new road.

The kinetic energy of the blocks reaches a maximum value of $1800 \mathrm{~J} \mathrm{~kg}^{-1}$ in some areas of the valley (Fig. 6d).

By these calculation programs it's not possible to expect a deterministic result supplying the exact value of the block speed during its fall, or its exact trajectory on the slope. Also disposing of a set of detailed data on the factors that influence the block's dynamic, (characteristic of the slope and loosening position) still remains an high uncertainty degree. With small variations of the initial conditions great variations in the final results are generated being "practically impossible to foresee the course of the process" (Baecher and Christian, 2003). A probabilistic approach is in these cases more powerful.

Due to the fact that it is not possible to stabilize the rock mass on the slope, the high probability of falling blocks reaching the temporary diversion tunnel justifies the necessity of constructing a tunnel between the villages of Campioli and Prequartera. The total cost of the new tunnel is estimated in near 30 millions of euros.

\section{CONCLUSION}

By means of a rock-fall probabilistic analysis of the Ceppo Morelli Landslide it was possible to verify that the temporary diversion road of the national road N549 constructed in the year 2000 connecting the two villages Prequartera and Campioli shows a certain risk of being reached by big blocks falling. The calculated frequency for this kind of event is of 0.147 event/year, that corresponds to 1 block each near 6 years and 9 months. For this reason a new tunnel between the villages of Campioli and Prequartera is foreseen, with a total estimated cost of 30 millions of euros.

\section{REFERENCES}

Australian Geomechanics Society, 2000. Landslide risk management. Australian Geomechanics Society. http://www.land.vic.gov.au/dpi/vro/coranregn.nsf/p ages/coran_landslides_risk?OpenDocument 
Baecher, G. and J. Christian, 2003. Reliability and Statistics in Geotechnical Engineering. Wiley, 1st Edn., New York, ISBN: 0471498335, pp: 618.

Biancotti, A. and S. Bovo, 1998. Regional distribution of rains and temperatures. Climate Stud. Piemonte, 1: 79-79.

Budetta, P. and A. Santo, 1994. Morphostructural evolution and related kinematics of rockfalls in Campania (southern Italy): A case study. Eng. Geol., 36: 197-210. DOI: 10.1016/00137952(94)90004-3

Cruden, D.M. and D.J. Varnes, 1996. Landslide Types and Processes. In: Landslides Investigation and Mitigation, Turner, A.K. and R.L. Schuster (Eds.). Transportation Research Board, Washington, DC., ISBN: 13: 978-0309062084, pp: 36-75.

Geo and Soft International, 2009. ISOMAP and ROTOMAP 3D surface modeling and rockfall analysis. Geo and Soft International. http://www.geoandsoft.com/manuali/english/rotom ap.pdf

Hoek, E., 1987. Rockfall-a program in BASIC for the analysis of rockfall from slopes. University of Toronto.
Pasquero, M., 1987. Dynamic of the block falls in the slope stability studies. Ph.D. Thesis, Politecnico di Torino.

Piteau, D.R. and R. Clayton, 1977. Discussion on paper: Computerized design of rock slopes using interactive graphics for the input and output of geometrical data. Proceeding 16th Symposium on Rock Mechanics, (RM'77), University of Minnesota, ASCE, pp: 62-63.

Scavia, C., 2004. The Ceppo Morelli Rockslide. In: Identification and Mitigation of Large Landslide Risks in Europe-Advances in Risk Assessment, Bonnard, C., F. Forlati and C. Scavia (Eds.). Routledge, USA., ISBN: 13: 978-9058095985, pp: 7-12.

Varnes, D.J., 1984. Landslide hazard zonation: A Review of principles and practice. UNESCO. http://www.bib.ub.edu/fileadmin/fdocs/landslideha zard.pdf 